\title{
World Journal of Pediatric Surgery \\ Bishop Koop conversion of temporary stoma can be an option to establish gut continuity early when primary anastomosis is not safe
}

Md Samiul Hasan, ${ }^{\odot}$ Ashrarur Rahman, Umama Huq, Kazi Nur UI Ferdous, Md Ayub Ali

To cite: Hasan MS, Rahman A, Huq U, et al. Bishop Koop conversion of temporary stoma can be an option to establish gut continuity early when primary anastomosis is not safe. World Jnl Ped Surgery 2019;2:e000025. doi:10.1136/wjps-2018-000025

Received 28 November 2018 Revised 12 February 2019 Accepted 12 February 2019

\section{Check for updates}

(c) Author(s) (or their employer(s)) 2019. Re-use permitted under CC BY-NC. No commercial re-use. See rights and permissions. Published by BMJ.

Pediatric Surgery, Bangladesh Institute of Child Health (BICH), Dhaka Shishu (Children) Hospital, Dhaka, Bangladesh

Correspondence to Dr Md Samiul Hasan; samiul045@gmail.com

\section{ABSTRACT}

Background Intestinal perforation and sometimes obstruction in neonates demand diverting stomas which are associated with fluid, electrolytes and nutrient loss. Early establishment of gut continuity is the key to the best outcome, though primary anastomosis is not always safe. The aim of this study was to evaluate the effectiveness of Bishop Koop stoma in establishing early continuity of gut and confirming the function of distal gut.

Methods Data of patients who underwent Bishop Koop conversion of diverting stoma from July 2016 to June 2018 were reviewed retrospectively. Demographic and outcome data were recorded and analyzed using Statistical Package for the Social Science (SPSS) V.22 software. Ethical permission was taken from hospital ethical committee. Results 29 patients were included ( 16 male and 13 female). Mean age of conversion was $5.8 \pm 2.5$ months and mean weight was $4.9 \pm 1.6$. Normal bowel movement was established in 26 patients. One patient died of sepsis on sixth postoperative day and one had anastomotic leakage. There was no significant difference with respect to outcome between perforation and obstruction group. Bishop Koop stomas were closed after 6 weeks of formation.

Conclusions Bishop Koop conversion of temporary stoma was turned out as a good choice for these patients.

\section{INTRODUCTION}

Neonatal intestinal perforation or sometimes obstruction demands diverting ileostomy or ileocolostomy. These procedures render the babies with high output stoma and its devastating consequences like fluid and electrolyte imbalance, protein energy malnutrition, etc, which are very difficult to manage in a setup without facilities for total parenteral nutrition (TPN), necessitating early establishment of intestinal continuity. Before closure of the stoma, we need to consider two points: patency and caliber of distal gut and function of distal gut.

Distal patency and caliber can be checked by distal loopogram. To confirm distal function, rectal biopsy is essential. Sometimes, these investigations leave us in confusion. When we find narrow colon in distal loopogram, it might be long segment Hirschsprung's disease (HD) or unused microcolon. When rectal biopsy fail to identify ganglion cell as well as thickened nerve bundle, we become more confused, is it a normal gut or a diseased gut. Absence of ganglion cell in H\&E stain without identification of nerve fibers with acetyl cholinesterase stain does not confirm HD. ${ }^{12}$ Unfortunately, like many centers in developing world, we too do not have acetyl cholinesterase stain and immunohistochemistry facilities. Expertise of the histopathologists should also be taken into consideration.

Moreover, diverting stoma at neonatal age leaves the distal gut unused for a long time. Even in the absence of HD, disparities of calibers make anastomosis difficult. Moreover, delayed establishment of peristalsis in unused gut and poor nutritional status of these patients with proximal stoma make the situation more complicated. Considering these facts, primary anastomosis remains always a high-risk situation.

Bishop Koop or distal chimney conversion of diverting stoma can help in this condition. As the stoma is present just proximal to anastomosis, it decompresses and reduces the load on anastomosis and ultimately secures the anastomosis. If distal gut is functionally normal, bowel will move normally and stoma will be functioning if distal obstruction is present. When the function of distal gut is established, stoma can be closed easily later at a suitable time. ${ }^{34}$

We wanted to evaluate the result of Bishop Koop stoma in these situations to confirm distal gut function and to reduce the rate of anastomotic disruption after stoma closure. 


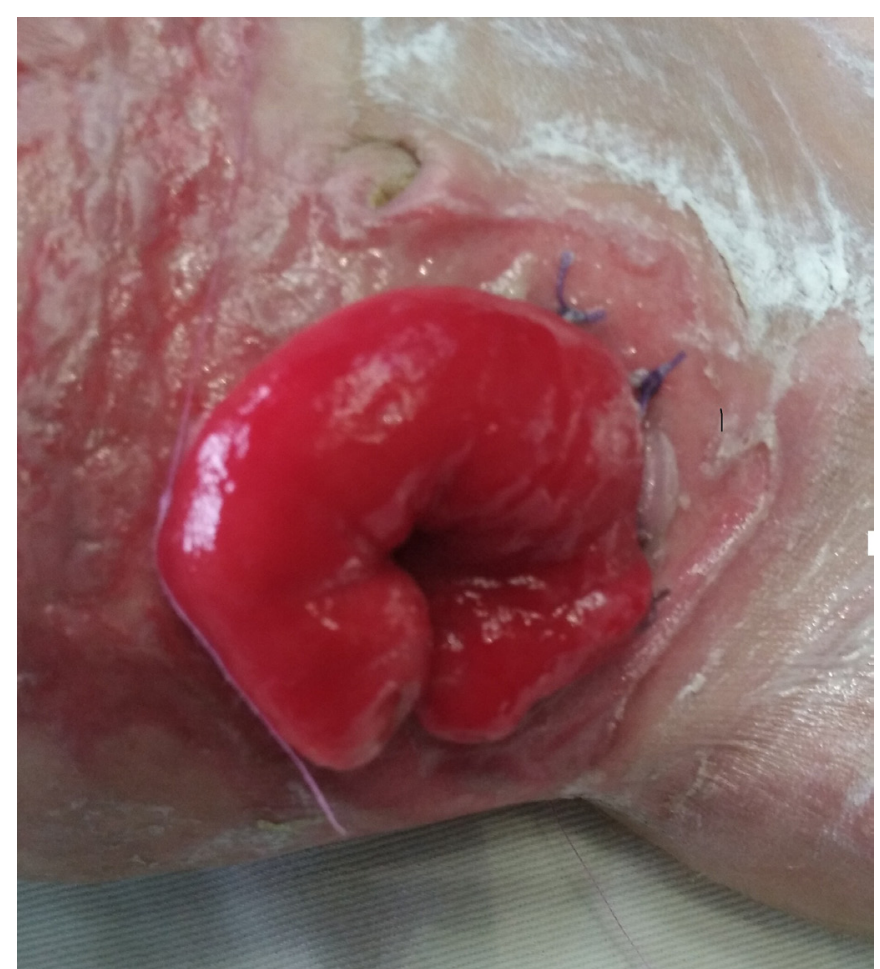

Figure 1 Diverting ileostomy.

\section{MATERIALS AND METHODS}

We have reviewed the data of all patients retrospectively who underwent Bishop Koop conversion of diverting stoma from July 2016 to June 2018.

Patients in whom diverting stoma was constructed in neonatal age either for perforation or obstruction of gut and having one of the following problems underwent Bishop Koop conversion:

1. Microcolon in distal loopogram.

2. Histopathology was inconclusive (shows the absence of ganglion cell and thickened nerve fiber).

3. Distal gut is unused for a long time and nutritional status is too poor to allow a stoma closure.

\section{OPERATION PROCEDURE}

Parents were counseled in detail regarding the situation and operative plan. Informed written consents were taken. Under general anesthesia, stoma was dismantled (figures 1 and 2). Distal patency was checked by warm normal saline irrigation. End of the proximal loop was anastomosed with the side of distal loop 4-5 cm distal to the opening (figure 3). Distal loop was then exteriorized.

After establishment of normal bowel movement, patients were discharged and advised to come after 6 weeks for stoma closure.

Data regarding patient's demography and operation outcome were collected from Surgery ward and operating room record. Data were analyzed using SPSS V.22 software. Numerical data were presented as mean $\pm \mathrm{SD}$, and categorical data were presented as percentage. Fisher's exact test was used to test the difference between categorical data.

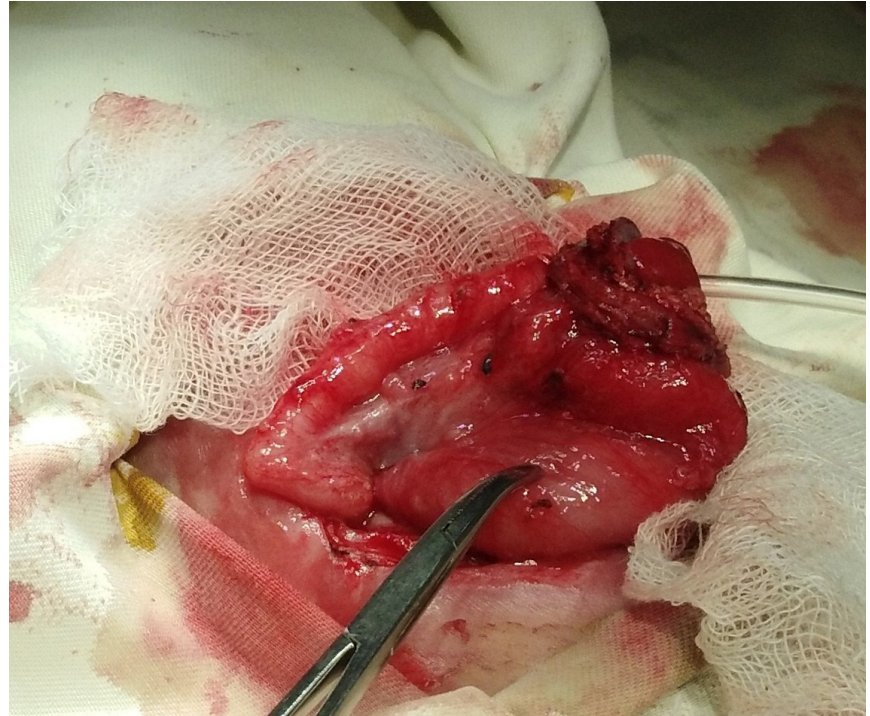

Figure 2 Dismantled stoma.

\section{RESULTS}

A total of 29 patients (male/female=16/13) underwent Bishop Koop conversion of temporary stoma during the study period. Their mean $( \pm \mathrm{SD})$ age was $5.8( \pm 2.5)$ years, and with a mean $( \pm \mathrm{SD})$ weight of $4.9( \pm 1.6) \mathrm{kg}$. Among them, 16 were boys and 13 girls. In 22 patients, stoma was created for intestinal perforation and meconium peritonitis; seven patients had neonatal intestinal

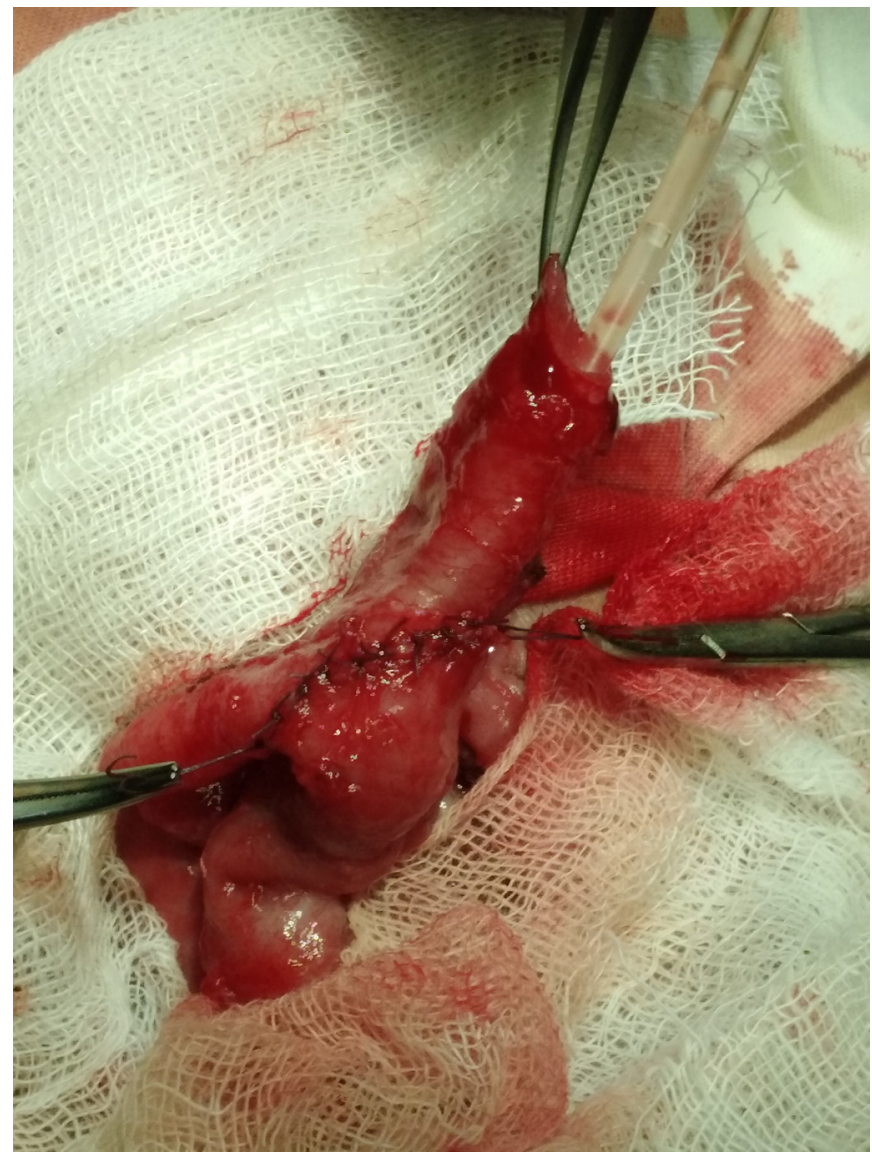

Figure 3 Bishop Koop anastomosis. 


\begin{tabular}{ll} 
Table $\mathbf{1}$ Diagnosis during first surgery & \\
\hline Diagnosis & $\mathbf{n = 2 9}$ \\
\hline Complicated meconium ileus & 8 \\
Necrotizing enterocolitis & 5 \\
Ileal atresia & 2 \\
Volvulus neonatorum & 3 \\
Intestinal perforation due to perinatal asphyxia & 4 \\
Intestinal obstruction & 7 \\
\hline
\end{tabular}

obstruction (table 1). Six patients had superficial wound infection and one had full thickness wound dehiscence necessitating mass closure (table 2). In one patient from perforation group and two patients from obstruction group, bowel movement did not establish. Among them, one patient developed anastomotic leakage and required laparotomy and diverting stoma again. One patient had persistent obstruction with overwhelming sepsis and died on fifth postoperative day. Another patient had functioning Bishop Koop stoma (table 3).

\section{DISCUSSION}

From the very beginning, we were facing problems with these patients as primary anastomosis was associated with high rate of failure. Exclusion of HD by rectal biopsy is very difficult due to multiple factors like inadequate tissue, unavailability of advanced stains and inadequate expertise of histopathologists. Even in the absence of HD, closure of this stoma is often problematic due to unused narrow distal colon. A locally feasible and affordable surgical technique could therefore save these patients from unnecessary resection pull through or primary anastomosis and their consequences.

Bishop Koop ileostomy was first described by Harry C Bishop and C Everett Koop in 1957 for meconium ileus. ${ }^{4}$ Since then, many authors found this technique modern and recommended this as a versatile procedure in pediatric surgery. It can be used in any situation where function of distal bowel is in doubt and primary anastomosis is likely to fail. ${ }^{56}$ Sehgal et al have used this technique as 'ostomy in continuity' for children with refractory short bowel syndrome from multiple causes and described it as a novel approach to establish intestinal autonomy and to minimize TPN-related complications. ${ }^{7}$ Peng et al have found Bishop Koop technique as very efficient for severe jejunoileal atresia. ${ }^{8}$

\begin{tabular}{ll}
\hline Table 2 Complications of operation & \\
\hline Complications & $\mathbf{n = 9}$ \\
\hline Anastomotic leakage & 1 \\
Wound infection & 6 \\
Full thickness wound dehiscence & 1 \\
Postoperative obstruction and sepsis & 1 \\
\hline
\end{tabular}

Table 3 Primary diagnosis and outcome of stoma conversion

\begin{tabular}{llllll}
\hline & \multicolumn{2}{c}{ Outcome } & & \\
\cline { 2 - 3 } & $\begin{array}{l}\text { Functioning } \\
\text { distal gut }\end{array}$ & $\begin{array}{l}\text { Non- } \\
\text { functioning } \\
\text { distal gut }\end{array}$ & & Total & P value \\
\hline $\begin{array}{l}\text { Primary diagnosis } \\
\text { Intestinal } \\
\text { perforation } \\
\text { Intestinal } \\
\text { obstruction }\end{array}$ & 21 & 1 & 22 & $\begin{array}{c}\mathbf{0 . 1 4} \\
\text { (Fisher's } \\
\text { exact test) }\end{array}$ \\
\hline Total & 5 & 2 & 7 & \\
\hline
\end{tabular}

This procedure is not uncommon even in our country rather very popular among pediatric surgeons for the management of meconium ileus and jejuno ileal atresia. ${ }^{9} 10$

Seven patients in this study had colostomy for neonatal intestinal obstruction. On laparotomy, no mechanical obstruction was found in these patients. Colon was uniformly dilated and narrow or transitional zone could not be identified. Biopsy from rectum revealed no ganglion cell and no thickened nerve bundle. So, sepsis or enterocolitis was assumed as the cause of these obstructions and Bishop Koop ileostomy was formulated. Results showed the decisions were worth to take.

In two patients from obstruction group and one patient from perforation group, distal bowel failed to function normally. Among the two patients of obstruction group, one patient had anastomotic leakage and required diverting stoma again. This patient is waiting for re-evaluation. Another patient had postoperative obstruction with sepsis and succumbed to death. The one patient from perforation group has functioning Bishop Koop stoma but not functioning distal gut and requires further evaluation. Though this difference is not statistically significant, a larger sample size could make the difference, and we need to be more careful in these patients to exclude functional obstruction (HD). Wound infection was the most common complication, may be due to unhealthy and contaminated peristomal tissue and poor nutritional status.

After establishment of normal bowel movement, we have closed the Bishop Koop stoma after 6 weeks. Though it requires an additional surgery, but at the end it benefits the patients as this procedure save the patients from consequences of high output stoma or an insecure primary anastomosis or even from a massive resection pull through and its consequences.

However, a comparison between Bishop Koop conversion and primary anastomosis would better validate this findings and this is a limitation of this study.

\section{CONCLUSION}

We found that Bishop Koop conversion of temporary stoma was very much effective in establishing early continuity of gut where primary anastomosis was not rational, 
and we recommend this procedure in centers with limited facility of TPN and histopathology.

Contributors MdSH contributed to the conception, study design, data collection, data analysis, manuscript writing and submission. AR contributed to the literature search, manuscript editing and critical appraisal. UH contributed to the data collection and manuscript editing. KMNF contributed to the study design and data analysis. MdAA obtained ethical permission and contributed to data collection and manuscript revision.

Funding The authors have not declared a specific grant for this research from any funding agency in the public, commercial or not-for-profit sectors.

Competing interests None declared.

Patient consent for publication Guardian consent obtained.

Ethics approval Taken from Dhaka Shishu (Children) Hospital ethical committee.

Provenance and peer review Not commissioned; externally peer reviewed.

Open access This is an open access article distributed in accordance with the Creative Commons Attribution Non Commercial (CC BY-NC 4.0) license, which permits others to distribute, remix, adapt, build upon this work non-commercially, and license their derivative works on different terms, provided the original work is properly cited, appropriate credit is given, any changes made indicated, and the use is non-commercial. See: http://creativecommons.org/licenses/by-nc/4.0/.

\section{REFERENCES}

1. Meier-Ruge W, Bruder E. Histopathological diagnosis and differential diagnosis of Hirschsprung's disease. In: Holschneider A, Puri P, eds. Hirschsprung's disease and allied disorders. Berlin: Springer, 2008: 185-97.

2. Szylberg L, Marszałek A. Diagnosis of Hirschsprung's disease with particular emphasis on histopathology. A systematic review of current literature. Prz Gastroenterol 2014;9:264-9.

3. Arsalani-Zadeh R, Kallam R, Khan S, et al. Early restoration of intestinal continuity in acute mesenteric ischaemia using BishopKoop stoma. Ann R Coll Surg Engl 2010;92:e23-4.

4. Bishop HC, Koop CE. Management of meconium ileus; resection, Roux-en-Y anastomosis and ileostomy irrigation with pancreatic enzymes. Ann Surg 1957;145:410-4.

5. Wit J, Sellin S, Degenhardt P, et al. Is the Bishop Koop anastomosis still modern in the treatment of newborn ileus? Chirurg 2000;71:307-10.

6. Kootstra G, Kamann HL, Okken A, et al. The Bishop-Koop anastomosis $-a$ find in pediatric surgery. Neth $J$ Surg 1980;32:92-6.

7. Sehgal S, Sandler AD, Alfred Chahine A, et al. Ostomy in continuity: a novel approach for the management of children with complex short bowel syndrome. J Pediatr Surg 2018;53:1989-95.

8. Peng $\mathrm{Y}$, Zheng $\mathrm{H}, \mathrm{He} \mathrm{Q}$, et al. Is the Bishop-Koop procedure useful in severe jejunoileal atresia? J Pediatr Surg 2018;53:1914-7.

9. Hasan MS, Mitul AR, Karim S, et al. Comparison of T tube ileostomy and bishop Koop ileostomy for the management of uncomplicated meconium ileus. J Neonatal Surg 2017;6.

10. Rahman MAM, Farooq MAA, Bhuiyan MAH, et al. Bishop Koop technique is preferred than primary anastomosis in managing jejunoileal atresia in a setup without neonatal intensive care unit our initial experience. J Paediatr Surg Bangladesh;3:5-11. 